\title{
Overview of the possible role of vitamin C in management of COVID-19
}

\author{
Anis Abobaker ${ }^{1}\left[\right.$ Aboubaker Alzwi ${ }^{2}$. Alsalheen Hamed A. Alraied ${ }^{3}$
}

Received: 22 September 2020 / Revised: 11 October 2020 / Accepted: 14 October 2020 / Published online: 28 October 2020

(c) Maj Institute of Pharmacology Polish Academy of Sciences 2020

\begin{abstract}
The mainstay of management of coronavirus disease 2019 (COVID-19) is mainly supportive as to date there is no effective antiviral treatment, apart from remdesivir which has been approved by Food and Drug administration (FDA) for treatment of COVID-19, or vaccine. Supplementation with micronutrients, such as vitamins and minerals, has gained an increasing interest as part of the supportive management of COVID-19. Vitamin C levels in serum and leukocytes are depleted during the acute stage of infection owing to increased metabolic demands. High-dose vitamin $\mathrm{C}$ supplement helps to normalise both serum and leukocytes vitamin $\mathrm{C}$ levels. Vitamin $\mathrm{C}$ has multiple pharmacological characteristics, antiviral, anti-oxidant, anti-inflammatory and immunomodulatory effects, which make it a potential therapeutic option in management of COVID19. The use of high dose of intravenous vitamin C for management of COVID-19 in China and the United Stated has shown promising results. There were no reported adverse reactions with the short-term use of high dose of vitamin C. Given the fact that vitamin $\mathrm{C}$ is cheap, available and safe drug with beneficial effects in management of viral infections and critically ill patients reported in previous clinical trials, it is sensible to add it to COVID-19 management protocol particularly if the current ongoing clinical trials testing the effect of vitamin C in management of COVID-19 show positive results.
\end{abstract}

Keywords Vitamin C C COVID-19 $\cdot$ SARS-CoV-2 $\cdot$ Beneficial effects $\cdot$ Management

\begin{tabular}{ll}
\multicolumn{2}{l}{ Abbreviations } \\
COVID-19 & Coronavirus disease 2019 \\
FDA & Food and Drug Administration \\
ARDS & Adult respiratory distress syndrome \\
EBV & Epstein-Barr virus \\
CMV & Cytomegalovirus \\
HSV-1 & Herpes simplex virus-1 \\
HIV & Human immunodeficiency virus \\
RCT & Randomised controlled trial \\
IV & Intravenous \\
VZV & Varicella zoster virus \\
URTI & Upper respiratory tract infection \\
SOFA & Sequential organ failure assessment \\
ICU & Intensive care unit \\
AIDS & Acquired Immune Deficiency Syndrome
\end{tabular}

Anis Abobaker

anis.abobaker@nhs.net

1 Spire Fylde Coast Hospital, St Walburgas road, Blackpool FY3 8BP, UK

27 th of October Hospital, Benghazi, Libya

3 Jomhorya Hospital, Benghazi, Libya

\section{Introduction}

Since the start of coronavirus disease 2019 "COVID-19" pandemic, multiple treatment regimens have been tried under the compassionate use indications. So far, no specific antiviral drug has been proven to be effective, apart from remdesivir which showed promising results and has gained an emergency approval by Food and Drug Administration (FDA) to be used in the treatment of COVID-19 [1,2]. That is why supportive treatment, including supplementation of micronutrients such as vitamin $\mathrm{C}$, has become a crucial part in management of COVID-19. It is noticed that serum and leukocyte levels of vitamin $\mathrm{C}$ is depleted during the acute stage of the infection $[3,4]$. Previous clinical trials found that supplementation with high dose of vitamin $\mathrm{C}$ decreased the severity and duration of respiratory viral infections [5]. Based on these findings, vitamin $\mathrm{C}$ might be used in management of COVID-19 as it might improve the immunological response against the novel coronavirus (SARS-CoV-2).

The pathological damage induced by SARS-CoV-2 infection is partially due to the direct viral virulence effect, but the main part is caused by massive host immune response and oxidative stress secondary to release of free radicals 
[5]. SARS-CoV-2 infection induces excessive release of proinflammatory cytokines, leading to cytokines storm, and increases production of reactive oxygen species which both cause significant lung damage which leads to subsequent development of adult respiratory distress syndrome (ARDS) [6,7]. ARDS can lead to further deterioration and development of septic shock which both are the common cause of intensive care unit (ICU) admission and mortality particularly in patients older than 60 years $[8,9]$. There is evidence showed that vitamin $\mathrm{C}$ is a potent anti-oxidant and has immunomodulatory effect [10-12]. Therefore, vitamin $\mathrm{C}$ can be used for treatment and prevention of complications of COVID-19.

In this review, we will discuss the various pharmacological effects of vitamin $C$ which could make it a potential option for prevention and treatment of COVID-19 (Fig. 1). In addition, we will discuss whether administration of high dose of vitamin $\mathrm{C}$ is safe or leads to development of adverse reactions.

\section{Antiviral properties of vitamin C}

There is multiple evidence from in vitro studies, animal experiments and clinical trials showed that vitamin $\mathrm{C}$ might have an antiviral effect. It is argued that high dose of vitamin $\mathrm{C}$ might have a virucidal effect because it inactivated viral multiplication in vitro [13]. In fact, this effect was related to catalytic reaction to the copper-containing media and not due to virucidal activities of vitamin C [13]. This conclusion is supported by the fact that the virucidal effect of vitamin $\mathrm{C}$ cannot be confirmed in vivo [10]. Vitamin $\mathrm{C}$ decreased activation of Epstein-Barr virus (EBV) early antigen, and supressed EBV viral load [14]. Pre-treatment of human foreskin fibroblast and endothelial cells, infected with cytomegalovirus (CMV), with vitamin $\mathrm{C}$ in combination with antiviral drugs such as ganciclovir and foscarnet, decreased viral replication, whereas treatment of the infected cells with antiviral drugs alone did not have a significant effect on viral replication [15]. Furthermore, vitamin C, not in combination with antivirals, supressed viral replication of herpes simplex virus-1 (HSV-1), influenza type A virus, poliovirus type 1 and rhinovirus $[16,17]$. In another in vitro study, a nutrient mixture, including vitamin $\mathrm{C}$, had a dose-dependent suppression effect on production of influenza viral nucleoproteins and neuraminidase activity [18]. Interestingly, exposure of chick embryo tracheal organ to vitamin $\mathrm{C}$ increased resistance of infection to coronavirus [19]. The same observation was noticed with broiler chicks in which resistance to infection with avian coronavirus was dependent on the dose of vitamin C [20]. In an animal experiment, treatment of Gulo knockout mice, which cannot synthesise vitamin C like human, with vitamin $\mathrm{C}$ had an in vivo antiviral immune response against influenza virus $(\mathrm{H} 3 \mathrm{~N} 2)$ by increasing the production of interferon alpha and beta [21]. In another study, treatment of monkeys infected with poliomyelitis

\section{The possible beneficial effects of vitamin C in management of COVID-19}

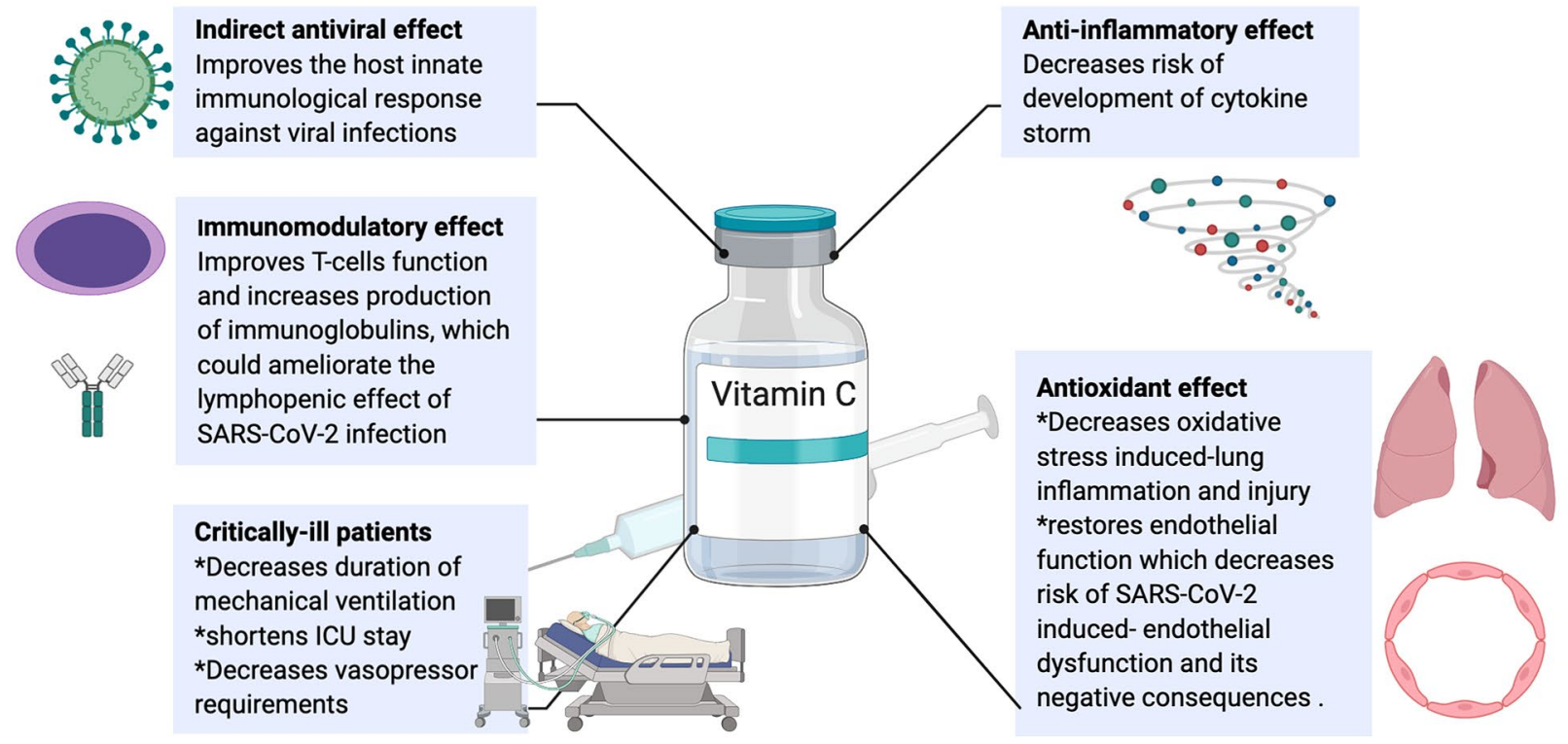

Fig. 1 The possible beneficial effects of vitamin C in management of COVID-19 (created with BioRender.com) 
with vitamin $\mathrm{C}$ reduced the risk of paralysis and improved survival [22]. The above pre-clinical data showed that vitamin $\mathrm{C}$ might have an antiviral effect against both DNA and RNA viruses. However, whether vitamin $\mathrm{C}$ has direct effect against viral replication in vivo cannot be confirmed. Alternatively, we believe that the antiviral effect of vitamin $\mathrm{C}$ is secondary to improved host immune response against viral infection as shown in Gulo knockout mice experiment [21].

The beneficial antiviral effect of vitamin $\mathrm{C}$ has been proven in many clinical studies. Low vitamin $\mathrm{C}$ level has been detected in patients with post-herpetic neuralgia [23]. A randomised controlled trial (RCT) showed that treatment of patients who had post-herpetic neuralgia with three doses of intravenous (IV) vitamin C (50 mg/kg/day) on days 1,3 and 5 improved the pain [23]. Treatment of acute varicella virus (VZV) infection in another RCT with IV vitamin C ( $5 \mathrm{~g} /$ day) on days 1,3 and 5 had no effect on improvement of acute pain. However, it significantly decreased the incidence of post-herpetic neuralgia [24]. In a retrospective study, it was found that the concentration of vitamin $\mathrm{C}$ in aqueous humour in the anterior chamber of the eye increased following oral supplementation of vitamin C [25]. Moreover, prophylactic oral antiviral and vitamin $\mathrm{C}$ decreased the recurrence rate of herpes simplex keratitis. It is argued that regular use of vitamin $\mathrm{C}$ supplement reduced the duration of common cold symptoms [26]. There is a conceptual believe that 1-2 g/day of vitamin $\mathrm{C}$ prevents upper respiratory tract infection (URTI) [27]. As this dose cannot be obtained from diet, oral vitamin $\mathrm{C}$ supplement might be recommended for people at risk of respiratory tract infection. It is hypothesised that a combined oral and inhalational vitamin $\mathrm{C}$ supplement maintain high level of vitamin $\mathrm{C}$ in bronchial epithelium and respiratory secretions which could have a protective antiviral effect against influenza virus [28]. Twenty-nine metaanalyses involving 11,077 participants showed that routine prophylaxis of high dose of vitamin $\mathrm{C}$ in normal population did not decrease the incidence of common cold [29]. However, six RCTs showed that vitamin C supplement decreased the incidence of common cold in 642 marathon runners, soldiers and skiers by 50\% [29]. The difference in the finding could be because the participants in the RCTs are exposed to more physical stress, which increases risk of infection compared with normal population, and that is why the prophylactic benefit of vitamin $\mathrm{C}$ has been detected in this highrisk group. An RCT showed that regular supplement of $1 \mathrm{~g}$ of vitamin $\mathrm{C}$ decreased the duration of illness but did not decrease the frequency of common cold [30]. This result was consistent with the finding of a meta-analysis which showed that oral vitamin $\mathrm{C}$ supplement between $500 \mathrm{mg}$ and $2 \mathrm{~g}$ /day did not decrease the incidence of viral URTI, but shortened the duration of illness by 1.6 days in children younger than 6 years [31]. In addition, a larger number of RCTs showed that daily supplement of $1 \mathrm{~g}$ vitamin $\mathrm{C}$ and
$30 \mathrm{mg}$ zinc decreased the duration and severity of symptoms in common cold [29]. A meta-analysis found that vitamin C supplement of more than $0.2 \mathrm{~g} /$ day in adults and $1-2 \mathrm{~g} / \mathrm{day}$ in children reduced duration and severity of common cold [32]. However, once the symptoms of common cold started, treatment with vitamin $\mathrm{C}$ did not have an effect on severity or duration of common cold [32]. In fact, when vitamin C was given in a higher dose ( $3 \mathrm{~g} /$ day), it improved the symptoms of common cold even if it was started after the onset of symptoms [33]. Furthermore, a meta-analysis of nine RCTs showed that extra-therapeutic dose of vitamin $\mathrm{C}$ at the onset of symptoms in addition to routine vitamin $\mathrm{C}$ supplement relieved common cold symptoms and decreased duration of illness [34]. Interestingly, oral and IV treatment with megadose of vitamin C (50-200 g/day) ameliorated symptoms in patients with Acquired Immune Deficiency Syndrome (AIDS), and reduced severity of opportunistic infections [35]. Based on the evidence from the above clinical studies, we can conclude that vitamin $\mathrm{C}$ might be effective in treatment of respiratory viral infections as well as other viral infections, such as HSV-1, VZV and human immunodeficiency virus (HIV), and its effect is dose dependent. The results of the studies which showed the antiviral effect of vitamin $\mathrm{C}$ in prevention and treatment of viral infections are summarised in Tables 1 and 2.

\section{Immunomodulatory effect of vitamin C}

Vitamin $\mathrm{C}$ could have a role in improving the function of innate immunity and enhancing cellular and humoral immune response. Evidence showed that inadequate intake of micronutrients, including vitamin $\mathrm{C}$, decreases resistance to infection and increases disease complications [36]. Vitamin $\mathrm{C}$ improves epithelial barrier integrity, which is the first line of defence against external pathogens [37]. Administration of vitamin $\mathrm{C}$ in high oral dose $(60 \mathrm{mg} / \mathrm{kg})$ enhanced natural killer cell activity, which play an important role in the innate immunity against viral infection [38]. Apparently, vitamin $C$ accumulates intracellularly in neutrophils which might suggest that vitamin $\mathrm{C}$ has a role in maintaining the normal function of leukocytes [39]. Furthermore, it appears that leukocyte vitamin $\mathrm{C}$ level as well as neutrophil function decline with age [40]. Administration of $1 \mathrm{~g} /$ day of IV vitamin $\mathrm{C}$ for 6 months to asthmatic children significantly improved neutrophil chemotaxis [41]. The same effect on neutrophil chemotaxis was observed in healthy volunteers when treated with vitamin $\mathrm{C}$ for 3 weeks in a weekly increasing-dose regime: $1 \mathrm{~g}$ for the first week, $2 \mathrm{~g}$ for the second week and $3 \mathrm{~g}$ for the third week [42]. Interestingly, multiple studies showed that the effect of vitamin $\mathrm{C}$ on phagocytic function of neutrophil is dose dependent. Vitamin $\mathrm{C}$ supplement in a dose of $200 \mathrm{mg}$ to $1 \mathrm{~g}$ daily for $1-4$ months 
Table 1 Summary of the results of the studies which used vitamin $\mathrm{C}$ for prevention of viral infections

\begin{tabular}{|c|c|c|c|c|}
\hline References & Viral infection & Type of study & Intervention & Effect \\
\hline Davelaar et al. [20] & Avian coronavirus & Pre-clinical (animal study) & $\begin{array}{l}\text { Treatment of broiler chicks with } \\
\text { different doses of vitamin } \\
\mathrm{C} \text { (ranging from } 7 \mathrm{mg} / \mathrm{kg} \text { to } \\
1320 \mathrm{mg} / \mathrm{kg} \text { ) }\end{array}$ & $\begin{array}{l}\text { Early vitamin } \mathrm{C} \text { supplement of } \\
300-330 \mathrm{mg} / \mathrm{kg} \uparrow \uparrow \text { resistance } \\
\text { of chicks to avian coronavirus } \\
\text { infection }\end{array}$ \\
\hline Kim et al. [25] & Herpes simplex & Retrospective cohort study & $\begin{array}{l}\text { Oral vitamin } C \text { treatment } \\
(1000 \mathrm{mg} \text { twice a day })\end{array}$ & $\begin{array}{l}\downarrow \downarrow \text { recurrence rate of herpes } \\
\text { simplex keratitis }\end{array}$ \\
\hline Hemila et al. [32] & Common cold & $\begin{array}{l}\text { Meta-analysis (based on the } \\
\text { analysis of } 29 \text { RCT results) }\end{array}$ & $\begin{array}{l}\text { Regular supplement of vitamin } \\
\mathrm{C}(\geq 0.2 \mathrm{~g} / \text { day })\end{array}$ & $\begin{array}{c}\text { No } \downarrow \downarrow \text { in incidence of common } \\
\text { cold in normal population }\end{array}$ \\
\hline Hemila et al. [32] & Common cold & $\begin{array}{l}\text { Meta-analysis (based on the } \\
\text { analysis of five RCT results) }\end{array}$ & $\begin{array}{l}\text { Regular supplement of vitamin } \\
C(\geq 0.2 \mathrm{~g} / \text { day })\end{array}$ & $\begin{array}{l}\downarrow \downarrow \text { incidence of common cold in } \\
642 \text { marathon runners, soldiers } \\
\text { and skiers by } 50 \%\end{array}$ \\
\hline Anderson et al. [30] & Common cold & $\mathrm{RCT}$ & $\begin{array}{l}\text { Oral vitamin C supplement } \\
\text { (1.0 g/day for 3-4 months) }\end{array}$ & $\begin{array}{l}\text { No } \downarrow \downarrow \text { in frequency of incidence } \\
\text { of common cold }\end{array}$ \\
\hline Vorilhon et al. [31] & Viral URTI & Meta-analysis & $\begin{array}{l}\text { Oral vitamin C supplement } \\
\text { (500 mg to } 2.0 \mathrm{~g} / \text { day })\end{array}$ & $\begin{array}{l}\text { No } \downarrow \downarrow \text { in incidence of viral URTI } \\
\text { in children }\end{array}$ \\
\hline Peter et al. [57] & Viral URTI & $\mathrm{RCT}$ & $\begin{array}{l}\text { Oral vitamin C supplement } \\
\quad(600 \mathrm{mg} / \text { day })\end{array}$ & $\begin{array}{l}\downarrow \downarrow \text { incidence of URTI after ultra- } \\
\text { marathon race }\end{array}$ \\
\hline Hemila et al. [66] & Pneumonia & $\begin{array}{l}\text { Meta-analysis (based on the } \\
\text { analysis of three prophylactic } \\
\text { RCT results) }\end{array}$ & $\begin{array}{l}\text { Oral vitamin } \mathrm{C} \text { supplement } \\
\text { (dose ranging between } 50 \mathrm{mg} / \\
\text { day and } 2.0 \mathrm{~g} / \text { day) }\end{array}$ & $\downarrow \downarrow$ incidence of pneumonia \\
\hline
\end{tabular}

improved neutrophilic phagocytic activity [43, 44]. However, administration of $2 \mathrm{~g}$ of vitamin $\mathrm{C}$ on a daily basis for 2 weeks impaired bacterial killing activity of neutrophil [45]. In addition, vitamin C might have an anti-apoptotic effect on peripheral blood neutrophils. Treatment of postoperative septic patients with $450 \mathrm{mg}$ /day of IV vitamin C for 6 days significantly reduced serum markers of neutrophil apoptosis [46]. As vitamin C improves epithelial barrier integrity, natural killer cell activity, neutrophil chemotaxis and phagocytosis, regular supplement of vitamin $\mathrm{C}$ could enhance the innate immune response against SARS-CoV-2 infection.

Multiple studies showed that experimentally induced vitamin $\mathrm{C}$ deficiency leads to impaired cellular and humoral immune response [47]. Age-related vitamin C deficiency is associated with low IgG and IgM serum levels [43]. Evidence showed that vitamin $\mathrm{C}$ enhances proliferation, differentiation and maturation of $\mathrm{T}$ lymphocytes in vitro [48, 49]. Supplementation of $1000 \mathrm{mg}$ of vitamin C daily for 42 days significantly reduced free radical-induced DNA damage in peripheral blood lymphocytes [50]. Intramuscular injections of vitamin c (500 mg/day for 1 month) improved T lymphocyte proliferation and cell-mediated immunity in elderly [40]. The same finding was observed in elderly women treated with a higher dose of vitamin $\mathrm{C}$ and vitamin $\mathrm{E}$ for longer period: $1 \mathrm{~g}$ vitamin C daily plus $200 \mathrm{mg}$ of vitamin $\mathrm{E}$ for 16 weeks [44]. An in vitro evidence showed that vitamin C increased production of immunoglobulins by peripheral blood lymphocytes [51]. Moreover, vitamin C supplement of $200 \mathrm{mg} /$ day for 1-3 months increased IgG and IgM serum levels and improved humoral immune response in elderly [43]. An animal study showed that vitamin $\mathrm{C}$ inhibited the negative immunoregulatory effect of $\mathrm{T}$ regulatory cells, which in turn enhanced $\mathrm{T}$ cell-medicated response leading to improvement of sepsis and sepsis-induced multi-organ failure [11]. Vitamin C modulates the release of various inflammatory mediators. Vitamin C supplement in mice increased release of interferon [52], which has an important role in enhancing cellular immune response against viral infection. Furthermore, vitamin $\mathrm{C}$ reduces the release of proinflammatory cytokines which might play a role in mitigating cytokine storm in SARS-CoV-2 infection which leads to reduction of inflammatory-induced tissue damage [53].In an animal study, vitamin $\mathrm{C}$ supplement reduced lung inflammation induced by influenza $\mathrm{A}$ virus and proinflammatory cytokine production in Gulo knockout mice [54]. In fact, SARS-CoV-2 infection has a significant negative impact on the immune system. It leads to lymphopenia and reduced numbers of natural killer cells in addition to inducing excessive release of inflammatory mediators leading to cytokine storm and tissue damage $[6,53]$. Based on the above findings, vitamin $\mathrm{C}$ might have the potential to ameliorate the deleterious immunological effect of SARS-CoV-2 infection which could make it a feasible treatment option in COVID-19.

\section{Anti-oxidant effect of vitamin C}

Multiple evidence reveal that vitamin $\mathrm{C}$ has a potent antioxidant effect. It acts directly as a scavenger of oxygen-free radicals. It also helps to restore other cellular anti-oxidants 


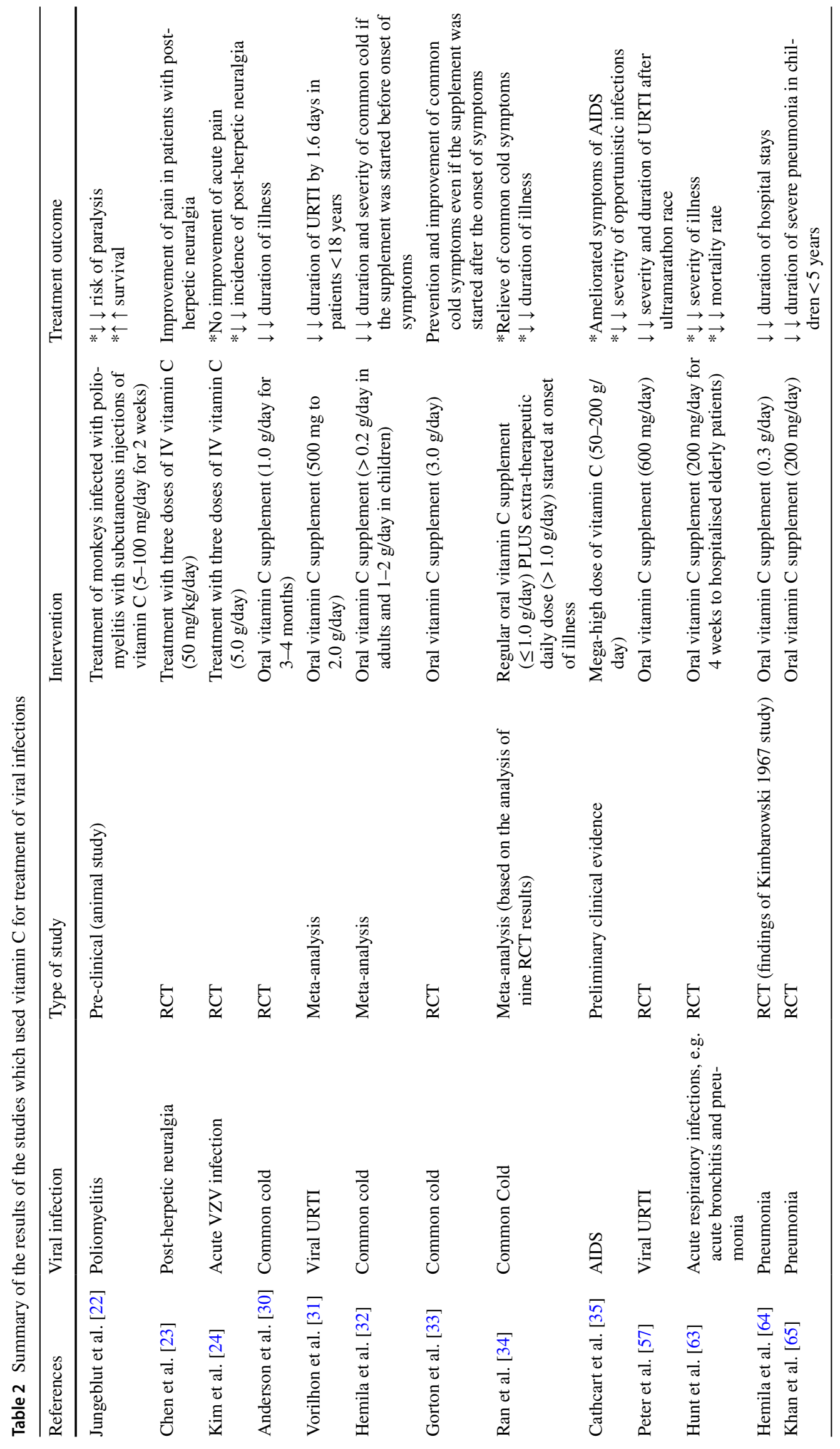


such as tetrahydrobiopterin and vitamin E [10]. In addition, vitamin $\mathrm{C}$ potentiates the anti-oxidant effect of polyphenols, such as flavonoids [55]. Vitamin C maintains redox integrity of the cells [29], which protects lungs against oxidative stress caused by infection and inflammation [56]. Vitamin C supplement of $600 \mathrm{mg}$ daily reduced incidence, severity and duration of URTI after ultramarathon race [57]. This might indicate that vitamin $\mathrm{C}$ decreases oxidative stress during strenuous physical activity through its anti-oxidant effect, which results in improved immunity. In another experiment, a single injection of paraquat (a herbicide) induced lung fibrosis in male mice by increasing the oxidative stress. Treatment of paraquat-induced lung fibrosis by vitamin $\mathrm{C}$ was beneficial, which was evident by detecting elevated levels of superoxide dismutase and catalase, natural antioxidant enzymes, in bronchoalveolar lavage fluid following treatment with vitamin C [58]. In fact, proinflammatory and pro-oxidant states are the main pathological processes which leads to development of ARDS [59]. Moreover, evidence from an animal study showed that anti-oxidants reduced viral-induced lung inflammation and injury [60]. Therefore, vitamin $C$ could be a potential option in treatment of pneumonia, prevention and treatment of ARDS in patients with COVID-19. However, doctors using high doses of vitamin $\mathrm{C}$ in treatment of COVID-19-related pneumonia and ARDS should remain vigilant as high concentrations of vitamin $\mathrm{C}$ can have a pro-oxidant effect [12].

\section{The role of vitamin $\mathrm{C}$ in prevention and treatment of pneumonia}

Vitamin $\mathrm{C}$ deficiency has been detected in association with pneumonia [61]. In fact, vitamin $\mathrm{C}$ body store is depleted in patients with acute presentation of chest infection because of oxidative stress and increased physiological demand [62]. Therefore, vitamin $\mathrm{C}$ supplements might be required during the acute stage of infection to restore normal vitamin C levels. An RCT showed that supplementation of $200 \mathrm{mg} /$ day of oral vitamin $\mathrm{C}$ for 4 weeks to hospitalised elderly patients with acute respiratory infections, e.g. acute bronchitis and pneumonia, improved the clinical outcome (reduced severity of illness and lowered mortality rate) [63]. The significant clinical improvement was noticed amongst the more severely ill patients [63]. Vitamin C supplements decreased duration of hospital stay in patients with pneumonia. The duration of hospital stay was shorter in patients receiving higher doses of vitamin C [64]. Treatment of children younger than 5 years diagnosed with pneumonia by $200 \mathrm{mg}$ of vitamin C once daily decreased duration of severe pneumonia. This was evident by a statistically significant quicker improvement in oxygen saturation and tachypnoea by 1 and 4 days, respectively in patients treated with vitamin $\mathrm{C}$ compared with placebo group [65]. It is argued that vitamin $\mathrm{C}$ has a role in prevention of pneumonia. Vitamin $\mathrm{C}$ and zinc supplements decreased incidence and improved outcome of pneumonia particularly in children [29]. In addition, results from three clinical trials showed that prophylactic supplements of vitamin $\mathrm{C}$ decreased incidence of pneumonia [66]. Based on the above evidence, we can conclude that vitamin $\mathrm{C}$ might be effective in prevention and treatment of COVID19-related pneumonia.

\section{The role of vitamin $C$ in management of ARDS, sepsis, septic shock and critically ill patients}

Vitamin C deficiency is commonly seen in patients with sepsis [67]. Furthermore, patients with septic shock have significantly depleted vitamin $\mathrm{C}$ levels compared with nonseptic patients [68]. In fact, there is an inverse correlation between serum level of vitamin $C$ in early sepsis and measures of multi-organ dysfunction [67]. In addition, vitamin $\mathrm{C}$ deficiency in critically ill patients is associated with increased vasopressor requirements, multi-organ failure and increased mortality [69]. Vitamin $\mathrm{C}$ has an anti-sepsis effect by reducing inflammatory response and oxidative stress as well as suppressing immunological dysfunction, which are the main pathophysiological mechanisms of sepsis [70]. Pre-clinical evidence showed that vitamin $C$ supresses excessive cytokine release leading to sepsis-induced organ dysfunction [67]. Sepsis leads to cellular immunosuppression. Treatment of mice with high dose $(200 \mathrm{mg} / \mathrm{kg})$ of IV vitamin $\mathrm{C}$ inhibited the negative immunoregulatory effect of $\mathrm{T}$ regulatory cells, which in turn enhanced $\mathrm{T}$ cell-mediated cellular immune response, and resulted in improvement of sepsis and sepsis-induced multi-organ dysfunction syndrome [11]. Therefore, vitamin $\mathrm{C}$ could be beneficial as a supportive treatment of sepsis and septic shock, which are common complications associated with COVID-19.

In phase I RCT, 24 patients with severe sepsis were treated with high doses of IV vitamin C (50-200 mg/ $\mathrm{kg} / 24 \mathrm{~h}$ ) for 4 days. Following the treatment, there was a reduction in sequential organ failure assessment (SOFA) score, a significant reduction in proinflammatory biomarkers (C-reactive protein and procalcitonin), and no significant rise in thrombomodulin which indicates less vascular injury [71]. In case of sepsis-induced ARDS, high-dose vitamin C treatment did not improve the clinical outcome. In a clinical trial, patients with sepsis-related ARDS requiring invasive mechanical ventilation received vitamin B1 (200 mg/day) and vitamin $\mathrm{C}(2 \mathrm{~g} /$ day $)$. The median duration of the treatment was 6 days. This regime did not improve mortality, and did not reduce the number of ventilator and intensive care unit (ICU)-free days [72]. In a multi-centre RCT, patients 
with sepsis and ARDS with less than 24-h onset treated with $50 \mathrm{mg} / \mathrm{kg} / 6 \mathrm{~h}$ of IV vitamin $\mathrm{C}$ for $96 \mathrm{~h}$. There was no change in multi-organ failure score after the treatment. Furthermore, there were no improvement neither in markers of inflammation (C-reactive protein) nor in markers of vascular injury (thrombomodulin). However, the mortality rate was significantly less in patients treated with high dose of IV vitamin C compared with placebo group [73]. Plasma cell-free DNA level was significantly lower after $48 \mathrm{~h}$ following treatment with high dose of IV vitamin C compared with placebo [74]. Apparently, high level of plasma cell-free DNA is associated with increased mortality in critically ill patients [74]. The significant improvement in mortality rate could be explained with the higher dose of vitamin C treatment used in the multi-centre RCT [73] compared with the other clinical trial [72]. A case report showed that treatment of 20-year-old patient presented with viral-induced ARDS with IV vitamin C $(200 \mathrm{mg} / \mathrm{kg} / 24 \mathrm{~h})$ in addition to ventilatory support resulted in rapid resolution of acute lung injury without long-term sequelae of ARDS, such as lung fibrosis [75]. The improvement in the clinical outcome in this case is most likely because of the young age of the patient and the absence of severe sepsis.

In a clinical trial, treatment of septic shock patients with high dose of IV vitamin $\mathrm{C}$ decreased vasopressor requirements and improved mortality [76]. Vitamin $\mathrm{C}$ is a cofactor for endogenous synthesis of catecholamines and adrenal steroid hormones, and this explains the reduced vasopressor requirements in patients with septic shock treated with high dose of vitamin C [77]. In another RCT, early treatment of septic shock with IV vitamin C $1.5 \mathrm{~g} / 6$ h reduced vasopressor requirements, shortened the duration of ICU stay, but unlike the previous study, did not improve mortality [78]. The combination of vitamin $\mathrm{C}$ with hydrocortisone and thiamine (HAT therapy) decreased morbidity and mortality in patients with severe pneumonia, sepsis and septic shock $[79,80]$. In the VITAMINS Randomized Clinical Trial, the combination of hydrocortisone, thiamine and IV vitamin $\mathrm{C}$ (HAT therapy) $1.5 \mathrm{~g} / 6 \mathrm{~h}$ did not lead to rapid improvement in septic shock compared with hydrocortisone alone [81]. This might indicate that HAT therapy is not superior to hydrocortisone alone in management of septic shock. However, the slight delay in the time-to-intervention of more than $30 \mathrm{~h}$ (after the onset of septic shock) could have an influence on the results of the study.

Vitamin C could play an important role in supportive management of critically ill patient. In fact, anti-oxidant treatment with vitamins $\mathrm{C}$ and $\mathrm{E}$ decreased duration of mechanical ventilation and shorten the length of ICU stay in critically ill surgical patients [82]. Meta-analysis showed that vitamin $\mathrm{C}$ as an adjuvant treatment shortened the duration of mechanical ventilation and ICU stay in non-surgical critically ill patients $[83,84]$. Although an individual study showed that treatment of septic patients requiring mechanical ventilation with IV vitamin C (6 g/day) did not improve mortality rate [85], a meta-analysis which enrolled 1210 patients from different clinical trials showed that treatment of critically ill patients with a dose ranging between 3 and $10 \mathrm{~g} /$ day of IV vitamin C decreased mortality rate [86]. In conclusion, all the above observations support the idea of using high dose of IV vitamin $\mathrm{C}$ as a part of the supportive management of severe COVID-19.

\section{The beneficial effect of vitamin C in management of COVID-19}

The use of IV vitamin C for treatment of COVID-19 in China has shown promising results. Administration of high dose of IV vitamin C reduced the risk of development of cytokine storm during the late stage of COVID-19 infection [12]. Evidence showed that nutritional support might have a role in management of COVID-19 [87]. Vitamin C in combination with curcumin and glycyrrhizic acid (VCG plus regime) promoted innate antiviral immunological response and prevented excessive inflammatory response which decreased the risk of inflammation-induced tissue damage [88]. A non-hospitalised patient with COVID-19 received a traditional Chinese medicine with a steroid-like effect called diammonium glycyrrhizinate in combination with vitamin $C$ [89]. This regime resulted in significant relieve of the patient's symptoms. As vitamin C potentiates the pharmacological effect of flavonoid [55], the combined use of vitamin C and Quercetin (a flavonoid drug) could have a synergistic antiviral effect [90]. Having said that, there is a suggestion that vitamin $\mathrm{C}$ and Quercetin can be used as an adjunctive treatment to other promising drugs, such as remdesivir, in management of COVID-19 [90]. Burn injury causes oxidative stress and generation of free radicals which lead to endothelial damage and increased capillary permeability [91]. The use of vitamin $\mathrm{C}$ in management of burn patients helped to restore endothelial function (possibly through its potent anti-oxidant effect) and decreased resuscitative IV fluid requirements [91]. Severe SARSCoV-2 infection leads to endothelial damage and dysfunction which consequently increases the risk of development of widespread micro- and macrovascular thrombosis and multiorgan failure [92]. As vitamin $\mathrm{C}$ has the ability to restore endothelial function, it might help to reduce the risk of development of this complication if used early in the course of management of COVID-19. Treatment with IV vitamin $\mathrm{C}$, as a monotherapy, might help to reduce lung inflammation and lung injury in COVID-19 [93]. An expert group on clinical treatment of COVID-19 in Shanghai advised that high dose of IV vitamin $\mathrm{C}$ is recommended to prevent cytokine storm in patients with mild or general symptoms 
of COVID-19 [94]. In fact, the use of high dose of IV vitamin $\mathrm{C}$ has been implemented in Chinese hospitals to treat hospitalised patients with COVID-19 [95]. Physicians in China stated that they have successfully treated 50 patients with moderate-to-severe COVID-19 with high dose of IV vitamin C: $10 \mathrm{~g}$ daily for moderate cases, and $20 \mathrm{~g}$ daily for severe case for 7-10 days. This treatment improved the clinical outcome. Compared with untreated group, this treatment regime shortened the duration of hospital stay by $3-5$ days, and there was no mortality reported in the treatment group [96]. A pulmonary and critical care physician in the United States stated that he treated COVID-19 patients admitted to his ICU with high dose of IV vitamin C (1500 mg, 4 times a day). A significant improvement was noticed compared with patients who did not receive IV vitamin $\mathrm{C}$ treatment [26]. Cheng et al. recommended early administration of high dose of vitamin C for treatment of COVID-19 pneumonia [97]. There is an ongoing clinical trial registered on clinicaltrials.gov website (NCT04264533) testing the effect of using mega high dose of IV vitamin C ( $24 \mathrm{~g} /$ day for 1 week) in treatment of severe COVID-19-related pneumonia. The study will be completed by the end of September 2020 . There are few other trials still in the recruitment stage registered on clinicaltrials.gov testing the effect of high dose of vitamin $\mathrm{C}$ for treatment of hypoxic COVID-19 patients (NCT04357782), treatment of sepsis of any cause, including COVID-19 (NCT03680274) and prevention of acute lung injury in COVID-19 (NCT04344184). Another registered trial with the reference number (NCT04342728) is testing the effect of vitamin $\mathrm{C}$ and zinc supplement in improving symptoms in patients with mild COVID-19. Based on the above evidence, vitamin $\mathrm{C}$ seems to have a role in treatment of COVID-19 in both inpatient and outpatient settings, leading to a beneficial effect in patients with mild symptoms, as well as patients with severe pneumonia, sepsis and ARDS. Therefore, we recommend to add vitamin $\mathrm{C}$ to the national treatment guidelines of COVID-19 particularly if the ongoing double-blinded RCTs provide promising results.

\section{The safety profile of vitamin C}

The recommended daily allowance of vitamin $\mathrm{C}$ for adults is $90 \mathrm{mg} /$ day [98]. During acute infection, a higher dose of vitamin $\mathrm{C}$ is required to meet the increased metabolic demand. According to the United States nutritional recommendation, the tolerable upper limit of the daily dose of vitamin $\mathrm{C}$ is $2 \mathrm{~g}$ [99]. Doses higher than $2 \mathrm{~g} /$ day can cause diarrhoea, abdominal pain and nausea, which are self-limited once the dose is reduced $[99,100]$. There is a concern that high dose of vitamin C ( $10 \mathrm{~g} /$ day) could lead to a supraphysiological level of vitamin $\mathrm{C}$ which causes oxaluria and increases the risk of oxalate nephropathy and oxalate kidney stone [101, 102]. In a randomised, crossover, controlled study, vitamin C supplement of $1000 \mathrm{mg}$ twice a day increased urinary oxalate in $40 \%$ of the participants, which in turn increases the risk of oxalate kidney stone [103]. Interestingly, in sepsis clinical trials, no series adverse effects, including kidney stones, have been reported to date [104]. This can be explained by the fact that vitamin $\mathrm{C}$ is water soluble, therefore, intoxication due to excessive intake of vitamin $C$ is unlikely as the concentration of vitamin $C$ which exceeds the body daily requirement will be excreted by the kidneys [47].

Treatment with high dose of vitamin $\mathrm{C}$ might interfere with the accuracy of the glucometer measurement of blood glucose level, as both vitamin C and Glucose have similar molecular structure, which could lead to false high blood glucose readings, and the diagnosis of clinically significant hypoglycaemia can be easily missed $[105,106]$. Therefore, clinicians should rely on laboratory blood samples or venous blood gases for measurement of blood glucose in patients treated with high dose of vitamin $\mathrm{C}$ to avoid missing the diagnosis of hypoglycaemia or increasing the risk of hypoglycaemia caused by unnecessary insulin treatment based on inaccurate glucometer readings [104]. A dose adjustment of vitamin $\mathrm{C}$ might be required in patients with renal impairment [107]. Therefore, high-dose vitamin C should be used with caution as impaired renal excretion of vitamin $\mathrm{C}$ might increase risk of vitamin toxicity. Moreover, treatment with high dose of vitamin $\mathrm{C}$ should be avoided in patients with glucose-6-phosphate dehydrogenase deficiency as it can lead to acute haemolysis [108]. In summary, the side effects of high dose of vitamin $\mathrm{C}$ for short-term use are almost negligible [107]. Therefore, the benefit of using high dose of vitamin $\mathrm{C}$ as part of the supportive management of COVID-19 hugely outweighs the risk of development of adverse reactions.

\section{Conclusion}

The mainstay of the management of COVID-19 at present is supportive. An important part of the supportive management is a nutritional support, and this includes micronutrient supplement including vitamin $\mathrm{C}$. Vitamin $\mathrm{C}$ might have an antiviral effect against multiple respiratory viruses in addition to other DNA and RNA viruses, such as HSV-1, EBV and HIV. This effect is most likely secondary to enhanced immunological response against viral infections rather than a direct effect against viral replication. Vitamin $\mathrm{C}$ has potent anti-oxidant and anti-inflammatory effects which reduce the chance of oxidative stress-related tissue damage and suppress excessive inflammatory response, known as cytokine storm. Vitamin $\mathrm{C}$ improves the host antiviral immune response by increasing the production of interferon and 
stimulating proliferation of lymphocytes. In previous clinical trials, vitamin C improved survival, decreased vasopressor requirements and shortened the length of ICU stay in critically ill patients and patients with severe sepsis and septic shock. Interestingly, treating COVID-19 patients with high dose of IV vitamin C in China and the United States have shown promising results. In addition, there were no reported adverse effects with short-term use of high dose of vitamin C. Therefore, given the pharmacological characteristics of vitamin $\mathrm{C}$ and its safe profile on high doses, we suggest to add vitamin $\mathrm{C}$ to the treatment protocol of COVID-19 particularly if the ongoing RCTs which are registered on clinicaltrials.gov provide positive results in the near future.

Author contributions AAb: background search, background reading, summarised the main ideas, and drafted the manuscript. AAl: background search, background reading, and revised the manuscript for important intellectual contents. AHAA: background search, background reading, and revised the manuscript for important intellectual contents.

Funding No financial or nonfinancial benefits have been received or will be received from any party related directly or indirectly to the subject of this article.

\section{Compliance with ethical standards}

Conflict of interest The authors declare that they have no conflict of interest.

\section{References}

1. Sanders J, Monogue M, Jodlowski T, Cutrell J. Pharmacologic treatments for coronavirus disease 2019 (COVID-19). JAMA. 2020. https://doi.org/10.1001/jama.2020.6019.

2. Bilbul M, Paparone P, Kim A, Mutalik S, Ernst C. Psychopharmacology of COVID-19. Psychosomatics. 2020. https://doi. org/10.1016/j.psym.2020.05.006.

3. Carr A, Rosengrave P, Bayer S, Chambers S, Mehrtens J, Shaw G. Hypovitaminosis $\mathrm{C}$ and vitamin $\mathrm{C}$ deficiency in critically ill patients despite recommended enteral and parenteral intakes. Crit Care. 2017a. https://doi.org/10.1186/s13054-017-1891-y.

4. Earar K, Arbune M, Dorobat C, Rusu-Negraia M, Stefanescu $\mathrm{V}$, Indrei L, et al. Biochemical effects and therapeutic application of vitamin C (C6H8O6) on COVID-19 infection. Rev Chim. 2020;71(5):473-8.

5. Bauer S, Kapoor A, Rath M, Thomas S. What is the role of supplementation with ascorbic acid, zinc, vitamin D, or N-acetylcysteine for prevention or treatment of COVID-19? Cleveland Clin J Med. 2020. https://doi.org/10.3949/ccjm.87a.ccc046.

6. Wang L, Wang Y, Ye D, Liu Q. Review of the 2019 novel coronavirus (SARS-CoV-2) based on current evidence. Int J Antimicrob Agents. 2020;55(6):105948.

7. Wu J. Tackle the free radicals damage in COVID-19. Nitric Oxide. 2020;102:39-41.

8. Wang D, Hu B, Hu C, Zhu F, Liu X, Zhang J, et al. Clinical characteristics of 138 hospitalized patients with 2019 novel coronavirus-infected pneumonia in Wuhan, China. JAMA. 2020;323(11):1061.
9. Kakodkar P, Kaka N, Baig M. A comprehensive literature review on the clinical presentation, and management of the pandemic coronavirus disease 2019 (COVID-19). Cureus. 2020. https://doi.org/10.7759/cureus.7560.

10. Colunga Biancatelli R, Berrill M, Marik P. The antiviral properties of vitamin C. Expert Rev Anti-infect Therapy. 2019;18(2):99-101.

11. Gao Y, Lu B, Zhai J, Liu Y, Qi H, Yao Y, et al. The parenteral vitamin $\mathrm{C}$ improves sepsis and sepsis-induced multiple organ dysfunction syndrome via preventing cellular immunosuppression. Mediators Inflamm. 2017;2017:1-12.

12. Boretti A, Banik B. Intravenous vitamin $C$ for reduction of cytokines storm in acute respiratory distress syndrome. PharmaNutrition. 2020;12:100190.

13. White L, Freeman C, Forrester B, Chappell W. In vitro effect of ascorbic acid on infectivity of herpesviruses and paramyxoviruses. J Clin Microbiol. 1986;24(4):527-31.

14. Uesato S, Kitagawa Y, Kaijima T, Tokuda H, Okuda M, Mou $\mathrm{X}$, et al. Inhibitory effects of 6-O-acylated 1-ascorbic acids possessing a straight- or branched-acyl chain on Epstein-Barr virus activation. Cancer Lett. 2001;166(2):143-6.

15. Cinatl J, Cinatl J, Weber B, Rabenau H, Gumbel H, Chenot J, et al. In vitro inhibition of human cytomegalovirus replication in human foreskin fibroblasts and endothelial cells by ascorbic acid 2-phosphate. Antiviral Res. 1995;27(4):405-18.

16. Koyama A, Uozaki M, Yamasaki H, Arakawa T, Arita M, Koyama A. Antiviral effects of ascorbic and dehydroascorbic acids in vitro. Int J Mol Med. 1998;22(4):541-5.

17. Schwerdt P, Schwerdt C. Effect of ascorbic acid on rhinovirus replication in WI-38 cells. Exp Biol Med. 1975;148(4):1237-43.

18. Jariwalla R, Roomi M, Gangapurkar B, Kalinovsky T, Niedzwiecki A, Rath M. Suppression of influenza A virus nuclear antigen production and neuraminidase activity by a nutrient mixture containing ascorbic acid, green tea extract and amino acids. BioFactors. 2007;31(1):1-15.

19. Atherton J, Kratzing C, Fisher A. The effect of ascorbic acid on infection of chick-embryo ciliated tracheal organ cultures by coronavirus. Adv Virol. 1978;56(3):195-9.

20. Davelaar F, van den Bos J. Ascorbic acid and infectious bronchitis infections in broilers. Avian Pathol. 1992;21(4):581-9.

21. Kim Y, Kim H, Bae S, Choi J, Lim S, Lee N, et al. Vitamin C is an essential factor on the anti-viral immune responses through the production of interferon- $\alpha / \beta$ at the initial stage of influenza A virus (H3N2) infection. Immune Netw. 2013;13(2):70.

22. Jungeblut C. Further observations on vitamin $C$ therapy in experimental poliomyelitis. J Exp Med. 1937;66(4):459-77.

23. Chen J, Chang C, Feng P, Chu C, So E, Hu M. Plasma vitamin C is lower in postherpetic neuralgia patients and administration of vitamin C reduces spontaneous pain but not brush-evoked pain. Clin J Pain. 2009;25(7):562-9.

24. Kim M, Kim D, Na C, Shin B. A study of intravenous administration of vitamin $\mathrm{C}$ in the Treatment of acute herpetic pain and postherpetic neuralgia. Ann Dermatol. 2016;28(6):677.

25. Kim G, Yoo W, Park M, Chung J, Han Y, Chung I, et al. Clinical features of herpes simplex keratitis in a Korean tertiary referral center: efficacy of oral antiviral and ascorbic acid on recurrence. Korean J Ophthalmol. 2018;32(5):353.

26. Simonson W. Vitamin $\mathrm{C}$ and coronavirus. Geriatr Nurs. 2020;41(3):331-2.

27. Zabetakis I, Lordan R, Norton C, Tsoupras A. COVID-19: the inflammation link and the role of nutrition in potential mitigation. Nutrients. 2020;12(5):1466.

28. Banerjee D, Kaul D. Combined inhalational and oral supplementation of ascorbic acid may prevent influenza pandemic emergency: A hypothesis. Nutrition. 2010;26(1):128-32. 
29. Wintergerst E, Maggini S, Hornig D. Immune-enhancing role of vitamin $\mathrm{C}$ and zinc and effect on clinical conditions. Ann Nutr Metab. 2006;50(2):85-94.

30. Anderson T, Reid D, Beaton G. Vitamin C and the common cold: a double-blind trial. Can Med Assoc J. 1972;107(6):503-8.

31. Vorilhon P, Arpajou B, Vaillant Roussel H, Merlin É, Pereira B, Cabaillot A. Efficacy of vitamin C for the prevention and treatment of upper respiratory tract infection. A meta-analysis in children. Eur J Clin Pharmacol. 2018;75(3):303-11.

32. Hemilä $\mathrm{H}$, Chalker E. Vitamin $\mathrm{C}$ for preventing and treating the common cold. Cochrane Database Syst Rev. 2013. https://doi. org/10.1002/14651858.CD000980.

33. Gorton $\mathrm{H}$, Jarvis K. The effectiveness of vitamin $\mathrm{C}$ in preventing and relieving the symptoms of virus-induced respiratory infections. J Manipulative Physiol Ther. 1999;22(8):530-3.

34. Ran L, Zhao W, Wang J, Wang H, Zhao Y, Tseng Y, et al. Extra dose of vitamin $\mathrm{C}$ based on a daily supplementation shortens the common cold: a meta-analysis of 9 randomized controlled trials. Biomed Res Int. 2018;2018:1-12.

35. Cathcart R. Vitamin $C$ in the treatment of acquired immune deficiency syndrome (AIDS). Med Hypotheses. 1984;14(4):423-33.

36. Calder P, Carr A, Gombart A, Eggersdorfer M. Optimal nutritional status for a well-functioning immune system is an important factor to protect against viral infections. Nutrients. 2020;12(4):1181.

37. Carr A, Maggini S. Vitamin C and immune function. Nutrients. 2017;9(11):1211.

38. Heuser G, Vojdani A. Enhancement of natural killer cell activity and $\mathrm{T}$ and $\mathrm{B}$ cell function by buffered vitamin $\mathrm{C}$ in patients exposed to toxic chemicals: the role of protein kinase-C. Immunopharmacol Immunotoxicol. 1997;19(3):291-312.

39. Liugan M, Carr A. Vitamin C and neutrophil function: findings from randomized controlled trials. Nutrients. 2019;11(9):2102.

40. Kennes B, Dumont I, Brohee D, Hubert C, Neve P. Effect of vitamin $\mathrm{C}$ supplements on cell-mediated immunity in old people. Gerontology. 1983;29(5):305-10.

41. Anderson R, Hay I, van Wyk H, Theron A. Ascorbic acid in bronchial asthma. S Afr Med J. 1983;63(17):649-52.

42. Anderson R, Oosthuizen R, Maritz R, Theron A, Van Rensburg A. The effects of increasing weekly doses of ascorbate on certain cellular and humoral immune functions in normal volunteers. Am J Clin Nutr. 1980;33(1):71-6.

43. Jayachandran M, Rani P, Arivazhagan P, Panneerselvam C. Neutrophil phagocytic function and humoral immune response with reference to ascorbate supplementation in aging humans. J AntiAging Med. 2000;3(1):37-42.

44. De la Fuente M, Ferrández M, Burgos M, Soler A, Prieto A, Miquel J. Immune function in aged women is improved by ingestion of vitamins $\mathrm{C}$ and E. Can J Physiol Pharmacol. 1998;76(4):373-80.

45. Shilotri $P$, Bhat K. Effect of mega doses of vitamin $C$ on bactericidal ativity of leukocytes. Am J Clin Nutr. 1977;30(7):1077-81.

46. Ferrón-Celma I, Mansilla A, Hassan L, Garcia-Navarro A, Comino A, Bueno P, et al. Effect of vitamin C administration on neutrophil apoptosis in septic patients after abdominal surgery. J Surg Res. 2009;153(2):224-30.

47. Mousavi S, Bereswill S, Heimesaat M. Immunomodulatory and antimicrobial effects of vitamin C. Eur J Microbiol Immunol. 2019;9(3):73-9.

48. Manning J, Mitchell B, Appadurai D, Shakya A, Pierce L, Wang $\mathrm{H}$, et al. Vitamin C promotes maturation of T-cells. Antioxid Redox Signal. 2013;19(17):2054-67.

49. Delafuente J, Prendergast J, Modigh A. Immunologic modulation by vitamin $\mathrm{C}$ in the elderly. Int $\mathrm{J}$ Immunopharmacol. 1986;8(2):205-11.
50. Brennan L, Morris G, Wasson G, Hannigan B, Barnett Y. The effect of vitamin $\mathrm{C}$ or vitamin $\mathrm{E}$ supplementation on basal and H2O2-induced DNA damage in human lymphocytes. Br J Nutr. 2000;84(2):195-202.

51. Tanaka M, Muto N, Gohda E, Yamamoto I. Enhancement by ascorbic acid 2-glucoside or repeated additions of ascorbate of mitogen-induced IgM and IgG productions by human peripheral blood lymphocytes. Jpn J Pharmacol. 1994;66(4):451-6.

52. Siegel B, Morton J. Vitamin C and the immune response. Experientia. 1977;33(3):393-5.

53. Stipp M. SARS-CoV-2: micronutrient optimization in supporting host immunocompetence. Int J Clin Case Rep Rev. 2020;2(2):01-10.

54. Kim H, Jang M, Kim Y, Choi J, Jeon J, Kim J, et al. Red ginseng and vitamin $\mathrm{C}$ increase immune cell activity and decrease lung inflammation induced by influenza A virus/H1N1 infection. J Pharm Pharmacol. 2016;68(3):406-20.

55. Jacob R. The integrated antioxidant system. Nutr Res. 1995;15(5):755-66.

56. Horowitz R, Freeman P. Three novel prevention, diagnostic, and treatment options for COVID-19 urgently necessitating controlled randomized trials. Med Hypotheses. 2020;143:109851.

57. Peters E, Goetzsche J, Grobbelaar B, Noakes T. Vitamin C supplementation reduces the incidence of postrace symptoms of upper-respiratory-tract infection in ultramarathon runners. Am J Clin Nutr. 1993;57(2):170-4.

58. Rodrigues da Silva M, Schapochnik A, Peres Leal M, Esteves J, Bichels Hebeda C, Sandri S, et al. Beneficial effects of ascorbic acid to treat lung fibrosis induced by paraquat. PLoS ONE. 2018;13(11):e0205535.

59. Calder P. Nutrition, immunity and COVID-19. BMJ Nutr Prevent Health. 2020;3(1):74-92.

60. Castro S, Guerrero-Plata A, Suarez-Real G, Adegboyega P, Colasurdo G, Khan A, et al. Antioxidant treatment ameliorates respiratory syncytial virus-induced disease and lung inflammation. Am J Respir Crit Care Med. 2006;174(12):1361-9.

61. Infusino F, Marazzato M, Mancone M, Fedele F, Mastroianni C, Severino P, et al. Diet Supplementation, probiotics, and nutraceuticals in SARS-CoV-2 infection: a scoping review. Nutrients. 2020;12(6):1718.

62. Carr A, Spencer E, Dixon L, Chambers S. Patients with community acquired pneumonia exhibit depleted vitamin $\mathrm{C}$ status and elevated oxidative stress. Nutrients. 2020;12(5):1318.

63. Hunt C, Chakravorty N, Annan G, Habibzadeh N, Schorah C. The clinical effects of vitamin C supplementation in elderly hospitalised patients with acute respiratory infections. Int J Vitam Nutr Res. 1994;64(3):212-9.

64. Hemilä H. Vitamin C and Infections. Nutrients. 2017;9(4):339.

65. Khan I, Shabbier A, Naeemullah S, Siddiqui F, Rabia M, Khan $\mathrm{S}$, et al. Efficacy of vitamin $\mathrm{C}$ in reducing duration of severe pneumonia in children. J Rawalpindi Med Coll. 2014;18(1):55-7.

66. Hemilä $\mathrm{H}$, Louhiala $\mathrm{P}$. Vitamin $\mathrm{C}$ for preventing and treating pneumonia. Cochrane Database Syst Rev. 2013;8:CD05532. https://doi.org/10.1002/14651858.CD005532.pub3.

67. Brant $\mathrm{E}$, Angus D. Is high-dose vitamin $\mathrm{C}$ beneficial for patients with sepsis? JAMA. 2019;322(13):1257.

68. Carr A, Rosengrave P, Bayer S, Chambers S, Mehrtens J, Shaw G. Hypovitaminosis $\mathrm{C}$ and vitamin $\mathrm{C}$ deficiency in critically ill patients despite recommended enteral and parenteral intakes. Crit Care. 2017b;21(1):1.

69. Marik P. Hydrocortisone, ascorbic acid and thiamine (HAT Therapy) for the treatment of sepsis. Focus Ascorbic Acid Nutr. 2018;10(11): 1762.

70. Li R, Guo C, Li Y, Qin Z, Huang W. Therapeutic targets and signaling mechanisms of vitamin $\mathrm{C}$ activity against sepsis: 
a bioinformatics study. Brief Bioinform. 2020. https://doi. org/10.1093/bib/bbaa079.

71. Fowler A, Syed A, Knowlson S, Sculthorpe R, Farthing D, DeWilde C, et al. Phase I safety trial of intravenous ascorbic acid in patients with severe sepsis. J Transl Med. 2014;12(1):32.

72. Yoo J, Kim R, Ju S, Lee S, Cho Y, Jeong Y, et al. Clinical impact of supplementation of vitamins $\mathrm{B} 1$ and $\mathrm{C}$ on patients with sepsis-related acute respiratory distress syndrome. Tuberc Respir Dis. 2020;83(3):248-54.

73. Fowler A, Truwit J, Hite R, Morris P, DeWilde C, Priday A, et al. Effect of vitamin $C$ infusion on organ failure and biomarkers of inflammation and vascular injury in patients with sepsis and severe acute respiratory failure. JAMA. 2019:322(13):1261.

74. Qiao X, Fisher B, Kashiouris M, Truwit J, Hite R, Morris P, et al. Effects of high dose intravenous vitamin C (IVC) on plasma cell-free DNA levels in patients with sepsis-associated ARDS. A60 lung injury, sepsis, and ARDS. Am Thorac Soc. 2019. https://doi.org/10.1164/ajrccm-conference.2019.199.1_ MeetingAbstracts.A2100.

75. Fowler A III, Kim C, Lepler L, Malhotra R, Debesa O, Natarajan $\mathrm{R}$, et al. Intravenous vitamin $\mathrm{C}$ as adjunctive therapy for enterovirus/rhinovirus induced acute respiratory distress syndrome. World J Crit Care Med. 2017;6(1):85.

76. Khalili H, Zabet M, Mohammadi M, Ramezani M. Effect of high-dose Ascorbic acid on vasopressor's requirement in septic shock. J Res Pharm Pract. 2016;5(2):94.

77. Patak P, Willenberg H, Bornstein S. Vitamin C is an important cofactor for both adrenal cortex and adrenal medulla. Endocr Res. 2004;30(4):871-5.

78. Nabil Habib T, Ahmed I. Early adjuvant intravenous vitamin C treatment in septic shock may resolve the vasopressor dependence. Int J Microbiol Adv Immunol. 2017;5:77-81.

79. Kim W, Jo E, Eom J, Mok J, Kim M, Kim K, et al. Combined vitamin $\mathrm{C}$, hydrocortisone, and thiamine therapy for patients with severe pneumonia who were admitted to the intensive care unit: Propensity score-based analysis of a before-after cohort study. J Crit Care. 2018;47:211-8.

80. Marik P, Khangoora V, Rivera R, Hooper M, Catravas J. Hydrocortisone, vitamin $\mathrm{C}$, and thiamine for the treatment of severe sepsis and septic shock. Chest. 2017;151(6):1229-38.

81. Fujii T, Luethi N, Young P, Frei D, Eastwood G, French $\mathrm{C}$, et al. Effect of vitamin $\mathrm{C}$, hydrocortisone, and thiamine vs hydrocortisone alone on time alive and free of vasopressor support among patients with septic shock. JAMA. 2020;323(5):423.

82. Nathens A, Neff M, Jurkovich G, Klotz P, Farver K, Ruzinski J, et al. Randomized, prospective trial of antioxidant supplementation in critically Ill surgical patients. Ann Surg. 2002;236(6):814-22.

83. Hemilä $\mathrm{H}$, Chalker E. Vitamin $\mathrm{C}$ may reduce the duration of mechanical ventilation in critically ill patients: a meta-regression analysis. J Intensive Care. 2020;8(1):15.

84. Hemilä H, Chalker E. Vitamin C can shorten the length of stay in the ICU: a meta-analysis. Nutrients. 2019;11(4):708.

85. Ahn J, Oh D, Huh J, Lim C, Koh Y, Hong S. Vitamin C alone does not improve treatment outcomes in mechanically ventilated patients with severe sepsis or septic shock: a retrospective cohort study. J Thorac Dis. 2019;11(4):1562-70.

86. Wang Y, Lin H, Lin B, Lin J. Effects of different ascorbic acid doses on the mortality of critically ill patients: a meta-analysis. Ann Intensive Care. 2019;9(1):58.

87. Briguglio M, Pregliasco F, Lombardi G, Perazzo P, Banfi G. The malnutritional status of the host as a virulence factor for new coronavirus SARS-CoV-2. Front Med. 2020. https://doi. org/10.3389/fmed.2020.00146.

88. Chen L, Hu C, Hood M, Zhang X, Zhang L, Kan J, et al. A novel combination of vitamin $\mathrm{C}$, curcumin and glycyrrhizic acid potentially regulates immune and inflammatory response associated with coronavirus infections: a perspective from system biology analysis. Nutrients. 2020;12(4):1193.

89. Ding H, Deng W, Ding L, Ye X, Yin S, Huang W. Glycyrrhetinic acid and its derivatives as potential alternative medicine to relieve symptoms in nonhospitalized COVID-19 patients. J Med Virol. 2020. https://doi.org/10.1002/jmv.26064.

90. Colunga Biancatelli R, Berrill M, Catravas J, Marik P. Quercetin and vitamin $\mathrm{C}$ : an experimental, synergistic therapy for the prevention and treatment of SARS-CoV-2 related disease (COVID-19). Front Immunol. 2020. https://doi.org/10.3389/ fimmu.2020.01451.

91. Rizzo J, Rowan M, Driscoll I, Chung K, Friedman B. Vitamin C in burn resuscitation. Crit Care Clin. 2016;32(4):539-46.

92. Pons S, Fodil S, Azoulay E, Zafrani L. The vascular endothelium: the cornerstone of organ dysfunction in severe SARSCoV-2 infection. Crit Care. 2020. https://doi.org/10.1186/ s13054-020-03062-7.

93. Hernández A, Papadakos P, Torres A, González D, Vives M, Ferrando C, et al. Two known therapies could be useful as adjuvant therapy in critical patients infected by COVID- 19 . Rev Esp Anestesiol Reanim. 2020;67(5):245-52.

94. Rozga M, Cheng F, Moloney L, Handu D. Effects of micronutrients or conditional amino acids on COVID-19-related outcomes: an evidence analysis center scoping review. J Acad Nutr Diet. 2020. https://doi.org/10.1016/j.jand.2020.05.015.

95. Anderson P. Intravenous ascorbic acid (IVAA) for COVID-19 supportive treatment in hospitalized COVID-19 patients (based on use in China and US settings) [Internet]. Cdn.ymaws.com. 2020. https://cdn.ymaws.com/naturopathic.org/resource/resmg r/documents/covid19/IVAA-COVID19-Hospital-Use-An.pdf. Accessed 11 Sept 2020

96. Cheng R. Hospital treatment of serious and critical COVID-19 infection with high-dose vitamin C. 2020. https://www.drwlc .com/blog/2020/03/18/hospital-treatment-of-serious-and-criti cal-covid-19-infection-with-high-dose-vitamin-c/. Accessed 2 Apr 2020.

97. Cheng R, Shi H, Yanagisawa A, Levy T, Saul A. Early large dose intravenous vitamin $\mathrm{c}$ is the treatment of choice for 2019nCov pneumonia [Internet]. Orthomolecular.org. 2020. https ://orthomolecular.org/resources/omns/v16n11.shtml?fbcli d=IwAR10Ak6G9QQBrwOaQsan7g_avChvizqPYqEL5w JI2-iP_LPve6ZWTYNrD64. Accessed 11 Sept 2020.

98. Bakare TA, Soar JS. A cost-effective preventative approach to potentially save lives in the coronavirus pandemic, jointly using vitamin $\mathrm{D}$, curcumin, and vitamin $\mathrm{C}$, (with updated dosage parameters). 2020. https://doi.org/10.35543/osf.io/cq8sa.

99. Hemilä H, Louhiala P. Vitamin C may affect lung infections. J R Soc Med. 2007;100(11):495-8.

100. Kim S, Yeom J. Reply: vitamin $\mathrm{C}$ as a possible therapy for COVID-19. Infect Chemother. 2020;52(2):224.

101. Nabzdyk C, Bittner E. Vitamin C in the critically illindications and controversies. World J Crit Care Med. 2018;7(5):52-61.

102. Adams K, Baker W, Sobieraj D. Myth busters: dietary supplements and COVID-19. Ann Pharmacother. 2020;54(8):820-6.

103. Massey L, Liebman M, Kynast-Gales S. Ascorbate increases human oxaluria and kidney stone risk. J Nutr. 2005;135(7):1673-7.

104. Kashiouris M, L'Heureux M, Cable C, Fisher B, Leichtle S, Fowler A. The emerging role of vitamin $\mathrm{C}$ as a treatment for sepsis. Nutrients. 2020;12(2):292. 
105. Kuhn S, Meissner K, Mayes L, Bartels K. Vitamin C in sepsis. Curr Opin Anaesthesiol. 2018;31(1):55-60.

106. Hager D, Hinson J, Rothman R. Vitamin C for sepsis and acute respiratory failure. JAMA. 2020;323(8):791.

107. Abat M, Larracas C, Cabaluna I. Should vitamin C/ascorbic acid infusion be used in the treatment of COVID-19? ACTA Medica Philippina. 2020;54:1-13.
108. Rees D, Kelsey H, Richards J. Acute haemolysis induced by high dose ascorbic acid in glucose-6-phosphate dehydrogenase deficiency. BMJ. 1993;306(6881):841-2. 